\title{
$\mathcal{A}$ Qualificasãa Jmplícita no Livro Jlustrado $\mathcal{A}$ Princesa Desejosa
}

\author{
The Implicit Qualification In the Illustrated BoOK \\ The Desirious PRINCESS
}

Beatriz dos Santos FERES*

Resumo: A investigação sobre a qualificação implícita em livros ilustrados para crianças tem como objetivo central identificar, nas encenações descritivas - sobretudo relativas à delimitação de personagens -, a função formativa subjacente às expressões nominais, às metáforas verbais e visuais e às ilustrações codificadas. Por qualificação implícita toma-se a caracterização dos seres operada sub-repticiamente e observável por via inferencial que, baseada em valores e crenças partilhados, constitui uma perspectiva de compreensão da realidade orientada por um grupo determinado histórica e socialmente. Parte-se do pressuposto que esse tipo de qualificação é um relevante fator de formação sociocultural e ideológica do indivíduo, que precisa ser levado em consideração no processo de desenvolvimento da competência leitora. Este trabalho fundamenta-se essencialmente na Teoria Semiolinguística (CHARAUDEAU, 2008, 2010), com destaque às noções de qualificação, modo descritivo de organização do discurso, patemização e competência linguageira. O livro intitulado "A princesa desejosa" (BIAZETTO, 2012) é tomado como corpus para análise.

Palavras-chave: Qualificação implícita. Livros ilustrados. Estratégias de leitura.

Abstract: The investigation about implicit qualification in illustrated books for children has its central aim in identifying, in the descriptive scenario mainly the related to character delimitation -, the developmental function underlying the noun phrases, verbal and visual metaphors, and the coded

* Doutora (2006) e Mestra (2003) em Estudos da Linguagem pela Universidade Federal Fluminense. Professora Adjunta (DE) do Instituto de Letras da UFF (RJ), Departamento de Letras Clássicas e Vernáculas. Contato: beatrizferes@yahoo.com.br. 
illustrations. By implicit qualification, there is the beings' characterization operated surreptitiously and also noticeable by an inferential via that, based on shared values and beliefs, constitutes a perspective of reality comprehension guided by a historically and socially determined group. It starts from the assumption that this kind of qualification is a significant factor in the individual's sociocultural and ideological building, which needs to be taken into account in the development process of reading competence. This study is essentially based on the Semiolinguistic Theory (CHARAUDEAU, 2008 , 2010), with emphasis on notions of qualification, descriptive mode of speech organization, pathemization, and language competence. The book entitled "The desirous princess" (BIAZETTO, 2012) is considered a corpus for analysis. Key-words: Implicit qualification. Illustrated books. Reading strategies.

\section{Proposta de Análise}

Considerando-se que os livros endereçados (também) às crianças apresentam uma conformação verbo-visual fortemente sedutora e, atrelado a esse fator, não só um conteúdo quase sempre inaugural sob o ponto de vista desse público-alvo, mas também fortemente marcado culturalmente, pode-se problematizar essa conformação, atribuindo-lhe um intuito formativo que busca integrar o leitor-criança em seu grupo social, a partir da disseminação, pela leitura, de crenças e valores, que, às vezes, se revelam mais preconceituosos, estereotipados; outras vezes, mais inovadores, questionadores; outras vezes, simplesmente identificatórios quanto ao grupo.

Assim, em termos de estratégias de disseminação de crenças e valores, elege-se a qualificação implícita como mecanismo aparentemente bastante produtivo. É na forma e no modo de identificação dos seres no mundo que se apreende a realidade sob o ponto de vista de um determinado grupo - e é a identificação o primeiro movimento descritivo de que se lança mão para ter acesso à realidade. Além disso, ao atribuir aos seres já nomeados características que os singularizam, assim como servem de comentários a seu respeito, denunciam-se, muitas vezes, aspectos valorizados ou não. É, sobretudo, nos sentidos implícitos - analisáveis discursivamente - que a maneira de entender o mundo é legado aos demais membros da coletividade. Se, de acordo com Kleiman (2009), os sentidos retidos na memória após a leitura de um texto são os que passaram pelo processo de inferenciação, 
provavelmente, a qualificação implícita deve se mostrar um recurso eficiente na propagação de crenças e valores.

Quanto ao signo imagético e sua particular forma de textualização, o que se pode destacar por ora é sua natureza igualmente referencial, categorizante, discursiva e comunicativa, cuja significação, porém, baseia-se em relações entre signo e objeto prioritariamente motivadas, assim como em sistemas singulares criados cotextualmente, nos quais incidem algumas convenções formais, como disposição na página, tamanho relativo, cores e tipos de traços.

Tanto quanto o signo linguístico, o imagético apresenta o mundo segundo coerções de ordem discursiva e pode adquirir diferentes graus de codificação, de acordo com sua recorrência e certa estabilidade funcional. A maior diferença parece ser de ordem processual. Como o signo imagético constitui-se de analogias, as qualidades do ser são apresentadas em sua forma, numa encenação descritiva mais direta (o que também pode ocorrer com o signo linguístico, mas conjuntamente com o processamento lógico). Além disso, sua textualização (quase) não linear hierarquiza elementos e informações de um modo particular, mais baseado em recursos voltados para a apreensão "global" de elementos e informações. Assim, a imagem, como signo, representa objetos e apresenta sentidos em sua concretude e, com isso, pode tomá-la como seu próprio fiador, a fim de seduzir a imaginação e, consequentemente, a cognição. Em outras palavras, a qualificação que o signo imagético produz, alguma dela sobreposta e/ou implícita, encontra respaldo, quase sempre, em sua própria configuração.

Para a investigação da qualificação implícitaacionada por expressões nominais, metáforas verbais e visuais e por ilustrações codificadas, a base teórica será a Semiolinguística (CHARAUDEAU, 1992; 2008; 2010), teoria de Análise do Discurso voltada para a compreensão das estratégias linguageiras a partir de seu entorno sociocognitivo e das circunstâncias imediatas que finalizam as trocas comunicativas. A essa base se juntarão outras noções necessárias à compreensão do processamento multimodal do gênero discursivo em pauta, como será visto. Para análise, será utilizado o livro A princesa desejosa (BIAZETTO, 2012).

\section{O Que Significa “Qualificar”}

"Qualificar" é, em síntese, um processo descritivo cujo objetivo precípuo é fazer-identificar entes de acordo com um ponto de vista. A 
"qualificação" é essencial à referenciação, seja na nomeação "categorizante" dos seres, seja em sua singularização por meio de termos adjetivos, ou ainda na apresentação de caraterísticas por meio de imagens codificadas e de metáforas.

Se, conforme Charaudeau (1992), descrever é uma operação que consiste, basicamente, em nomear, localizar-situar e qualificar os seres, é preciso considerar que essa operação é sempre circunstanciada em função de uma tomada de posição (não é possível apontar e descrever seres em sua totalidade, mas tão-somente na perspectiva assumida pelo descritor). Em outras palavras, não se deve ignorar que o processo descritivo atende às formulações e coerções advindas do conhecimento sociocognitivo acionado pelo produtor em função da troca comunicativa de que participa. Disso se conclui que não há descrições ou referências a priori, mas construtos localizados, que instauram objetos de discurso interpretáveis em relação ao contexto e aos saberes partilhados por um grupo social. Assim, na "qualificação", elegem-se características, qualidades, que retratam o mundo perspectivamente, de acordo com um modo de olhar, através de um filtro ao mesmo tempo biológico/perceptivo e cultural/interpretativo: "Para que um ser exista, é preciso que ele receba uma identidade. Essa identidade é o resultado da maneira como o homem percebe e constrói o mundo" e "como as propriedades são o resultado da maneira como o homem percebe e constrói a significação do mundo, elas testemunham igualmente o modo de visão que o homem-sujeito falante projeta sobre as qualidades dos seres" (CHARAUDEAU, 1992, p. 325-326 - versão nossa).

Ainda segundo Charaudeau (1992), esse modo de visão pode ser objetivo (relativo à percepção física, ao conhecimento antropológico, ou sobre a identidade social dos seres), subjetivo (relativo à apreciação do sujeito falante, seja no domínio intelectivo, afetivo, estético, ético, ou pragmático), ou objetivo relativo (que depende da avalição do sujeito falante quanto à distância, ou à dimensão, e suscetível de contestação). A qualificação, portanto, pode ser entendida como o processo que consiste em atribuir propriedade(s) a um ser a fim de incluí-lo em um conjunto "categorizante" de acordo com um modo de olhar. Como esta análise se restringe à qualificação implícita, serão enfatizados os recursos discursivos, subjacentes ao processo descritivo em si, que indicam valores e crenças disseminados socialmente, e, de certa maneira, serão secundarizadas as descrições mais objetivas e/ou explícitas (a não ser quando servirem de base à qualificação implícita). 
Desse modo, como qualificação implícita toma-se a qualificação subjacente a elementos textuais e inferível na relação com o discurso e com a situacionalidade comunicativa. Essa ideia extrapola aquilo que Charaudeau (2008) trata como qualificação. Para o analista, esta pode ser objetiva ou subjetiva e desenvolve-se por meio da adjetivação e da analogia (explícitas ou implícitas). Já para esta análise, a qualificação implícita não se restringe aos meios mencionados, mas aos de implicitação qualitativa, que pode estar reservada à própria nomeação, em expressões nominais, ou subentendida em uma caracterização explícita, e em imagens metafóricas, ou ainda em ilustrações codificadas, cujo valor simbólico é reconhecido socialmente.

\section{Pertinências Quanto ao Livro Ilustrado para Crianças}

Justifica-se a preferência por livros ilustrados para crianças para a composição do corpus pela estreita relação entre as formas da encenação descritiva e o caráter formativo que esse tipo de material parece apresentar. Em geral, todo produto de uma cultura é moldado de acordo com coerções de ordem ideológica mais ou menos implícitas na textualização. Ainda que se verifique uma maior preocupação por parte da atual produção de livros para crianças quanto à rejeição a propostas “pedagogizantes", acredita-se na presença de convenções e valores marcados de diversas maneiras em um produto endereçado a priori a um "leitor-modelo" em início de conformação social. Assim, a simples inserção sociocultural desse tipo de livro, somada a seu endereçamento, já assinalariam seu caráter formativo.

Como gênero, que se estabiliza minimamente em forma e propósito comunicativo, pode-se afirmar que o livro ilustrado para crianças apresenta semiose verbo-visual, caráter estético e, frequentemente, forma narrativa com duplo endereçamento (a criança e o adulto, este quase sempre mediador da leitura). Pode manifestar diferentes graus de complexidade constitutiva, seja pelo tipo de integração entre a linguagem verbal e a visual, seja pela presença ou não de um narrador que "preenche lacunas" de mais difícil solução por parte das crianças, não acostumadas com a lógica narrativa, ou com o léxico variado. Essas características valorizam a investigação sobre a qualificação implícita, pois, relacionadas entre si e com o contexto sociocultural em que se inserem, podem contribuir para a compreensão da referenciação, instituída pelo verbal e/ou pelo visual, assim como do funcionamento das metáforas verbais e visuais e sua capacidade implicitadora, além da 
possibilidade de se averiguar a discursivização de valores e crenças nesse gênero em particular.

Como o próprio nome sugere, o livro ilustrado para crianças é um gênero cujo público-alvo é preferencialmente (mas não exclusivamente) a criança, tida como um leitor em início de formação como ser social, que, aos poucos, passa a compreender os rituais de seu grupo, suas crenças e seus valores. Para isso, em geral, esse público conta com a colaboração do adulto, mediador de leitura, que costuma não só orientar a interpretação do texto, como também servir de modelo para a posterior leitura autônoma da criança, seja esmerando-se no padrão prosódico e rítmico da oralização da parte verbal do texto, seja intervindo no preenchimento de alguma lacuna informacional ou inferencial que ele percebe ter sido deixada vazia pela criança.

Cada nova releitura, tanto de palavras como de imagens, cria pré-requisitos melhores para uma interpretação adequada do todo. Presume-se que as crianças sabem disso por intuição quando pedem que o mesmo livros seja lido para elas em voz alta repetidas vezes. $\mathrm{Na}$ verdade, elas não leem o mesmo livro; elas penetram cada vez mais fundo em seu significado. É muito comum os adultos perderem a capacidade de ler os livros ilustrados dessa maneira, porque ignoram o todo e encaram as ilustrações como meramente decorativas. É quase certo que isso seja relacionado com a posição dominante da comunicação verbal, particularmente a escrita, em nossa sociedade, embora ela esteja em declínio em gerações educadas na televisão e agora nos computadores. (NICOLAJEVA; SCOT'T, 2011, p. 14).

A criança costuma se fixar em cada detalhe do texto, sem hierarquizar elementos ou significados; já o adulto, habituado com a estrutura textual, costuma se concentrar no eixo evolutivo da trama, e/ou do tema. O movimento de antecipação e de focalização que apenas o leitor mais experiente domina e que é fundamental para a criação de expectativas durante a leitura é, em geral, orientado pelo adulto e, dessa maneira, ensina-se um padrão interpretativo culturalmente atestado. Pode-se observar que, em vez de sugerir o público leitor em função de rótulos ou de sua apresentação, o próprio livro prescreve o nível de leitura, mais previsível, "pré-digerido", com pouca dedução ou qualquer demanda de contribuição por parte do 
leitor, ou menos previsível, exigindo mais interação e dedução, mais investimento do leitor para as inferências exigidas pelo texto - como todo livro pode fazer, mesmo aquele não classificado como "infantil". Além disso, é o adulto quem compra o livro para a criança, mesmo que lhe dê liberdade para escolhê-lo, então é também um leitor em potencial a quem se deve dirigir o mercado editorial envolvido com esse gênero.

Muitos livros ilustrados são claramente destinados a crianças pequenas e adultos sofisticados, comunicando-se em diversos níveis com ambos os públicos. Procurando por Atlântida (1993/1998), de Colin Thompson, é um excelente exemplo de livro que toca um público amplo, do não leitor ao adulto letrado. Os adultos estão completamente embebidos nas convenções dos livros e são experientes em decodificar o texto de forma tradicional, seguindo o esperado desenrolar temporal de acontecimentos e leitura da esquerda para a direita. Mas os intricados iconotextos de Thompson, com ilustrações abrangendo uma multiplicidade de minicenas e eventos pictóricos tangenciais, são perfeitamente adequados ao olhar menos exercitado, porém perspicaz, da criança. Dessa forma, o autor nivela o campo de jogo para seu público variado exigindo habilidades menos tuteladas de percepção e decodificação de imagens. É evidente que o melhor público é um time de adultos e crianças reunidos, cada um oferecendo seus pontos fortes especiais. (NICOLAJEVA; SCOTT, 2011, p. 39).

Apesar de esse duplo endereçamento latente, ou mesmo por causa dele, o livro ilustrado e os outros gêneros componentes da dita "literatura infantil" tendem a ser tomados, atualmente, simplesmente como livros, como produtos culturais que têm como público alvo também as crianças. Sua categorização, como já se afirmou aqui, incide, sobretudo, em aspectos organizacionais, e não em uma estética e uma complexidade estrutural subvalorizada.

A natureza multimodal dos livros ilustrados para as crianças pode ser tida como característica primeira de sua constituição, além de profícua base para a construção de sentidos. Muito diferente do que se acostumou a apregoar a respeito dos livros infantis "cheios de figuras", na atualidade, pode-se atribuir ao livro ilustrado as características de objeto de cultura, com configuração estética e função sensibilizadora. A complexidade de sua 
configuração multimodal é atestada por vários autores, dentre os quais se destacam Nicolajeva e Scott (2011), em obra específica. Para elas, tanto as figuras quanto as palavras demonstram finalidades específicas nessa configuração multimodal, segundo a natureza de cada realização semiótica:

As figuras nos livros ilustrados são signos icônicos complexos, e as palavras, signos convencionais complexos; [...]. A função das figuras, signos icônicos, é descrever ou representar. A função das palavras, signos convencionais, é principalmente narrar. Os signos convencionais são em geral lineares, diferentes dos icônicos, que não são lineares nem oferecem instrução direta sobre como lê-los. A tensão entre as duas funções gera possibilidades ilimitadas de interação entre palavra e imagem em um livro ilustrado. (NICOLAJEVA; SCOTT, 2011, p. 14).

Essa configuração, portanto, carrega um pressuposto quanto aos sentidos e efeitos de sentido programáveis no e pelo texto, pois, para além dos recursos apresentados especificamente pelo caráter verbal ou pelo caráter visual, a conjunção das linguagens garante um novo nível de complexidade, devido à integração de componentes de origens distintas e de acionamento cognitivo também diferente. O ritmo do livro ilustrado, seu maior dinamismo e poeticidade dependem, em grande parte, da fusão, ou da complementaridade dessas realizações.

\section{O Que Implica A Princesa Desejosa}

Tratando-se de uma análise predominantemente discursiva, a destinação do livro A princesa desejosa torna-se fator primordial de categorização: é um livro feito para crianças, cujo público-alvo pode ser identificado por indícios deixados no próprio texto, como a abordagem de tema de interesse do público infantil, sobretudo; estruturas que, de certo modo, incluem informações sobre o mundo e seu funcionamento que se presumem desconhecidos pelas crianças (a semiose dupla, verbo-visual, serve, muitas vezes, a esse objetivo); um tratamento diversificado de sua literariedade, dentre outros aspectos. Analisa-se a conformação textual vinculada ao contexto sociodiscursivo e à situacionalidade recorrente no uso desse tipo de livro. Pretende-se, aqui, investigar a proposta verificável na textualização 
e pela discursivização com que se conforma o livro, e não pelos resultados possivelmente identificados na extremidade da recepção leitora.

Em A princesa desejosa (BIAZETTTO, 2012), a protagonista a que se refere o título é temida desde que nasce por causa de seu insaciável desejo de ter absolutamente tudo só para si. Tornando-se solitária, passa a desejar, acima de tudo, uma companhia, concretizada, após muito sofrimento, na figura do Príncipe Viajante que, curioso, segue um rio de lágrimas até que a encontra. A paixão pelo príncipe passa a representar seu maior e único desejo e, enfim, a princesa tem sua insaciabilidade superada.

Em um reino não muito longe daqui, vivia uma jovem princesa diferente de todas as princesas sobre as quais já se ouviu contar.

Ela era temida por todos, adultos e crianças. Tão temida que nem o seu nome ousavam pronunciar. E por chamarem-na sempre de Princesa Desejosa, acabaram por esquecer seu verdadeiro nome. (BIAZETTO, 2012, p. 1).

As expressões nominais a que a qualificação implícita pode se ligar limitam-se àquelas cujo sentido implícito é de cunho avaliativo (singularizador ou especificador), ou seja, não se trata de um sentido de língua que as expressões podem igualmente significar, mas tão-somente uma característica subentendida, seja porque as expressões contêm um caráter representacional que, ao serem inseridas num contexto, salienta um sentido indireto, mais ou menos convencional, seja porque esse elemento é potencialmente um produtor de efeitos (patêmicos, humorísticos, estigmatizantes). Mesmo considerando-se variável a complexidade estrutural das expressões nominais, observa-se sua capacidade qualitativa tomando como foco seu núcleo nominal, ou um possível traço sêmico que induza à qualificação; a adjetivação avaliativa, em suas várias formas, e as cadeias referenciais.

A expressão definida a princesa desejosa contém, sob a explicitude de uma caracterização que singulariza a personagem, alguns traços avaliativos relevantes. Em primeiro lugar, a expressão definida que exalta a qualidadede ser desejosa substitui o nome da princesa, cuja referência direta e objetiva se esquiva, esquecida por todos diante do medo que sentiam dela: a (terrível) qualidade torna-se sua própria e única referência. Além disso, o núcleo nominal da expressão princesa, em si, está impregnado de valores que participam do imaginário coletivo. Conforme o Dicionário de símbolos 
(CHEVALIER; GHEERBRANT, 2009, p. 744), “o príncipe e a princesa são a idealização do homem e da mulher, no sentido da beleza, do amor, da juventude, do heroísmo”. Perpetuado socialmente, o símbolo da princesa inclui ideias como da feminilidade, delicadeza, fragilidade, todas avaliadas positivamente em relação àquilo que referem. A princesa desejosa, no entanto, é descrita como "uma jovem princesa diferente de todas as princesas sobre as quais já se ouviu contar" (BIAZETTO, 2012, p. 1). Embora essa caracterização rompa com o ideal propagado pela representação de uma princesa, o fato de ainda se utilizaro nome princesaguarda, em sua imanência, a possibilidade de emergência desse ideal feminino ao longo da história - o que se comprova na "desinversão" de valores operada no momento de retorno ao equilíbrio narrativo, ao final da história. Quanto ao adjetivo desejosa, explicitador da característica que serve de motivação para o conto, vale salientar que se deriva de desejo, a partir da sufixação em-oso, significando "cheia de desejo". "Desejo", substantivo que dá a base do adjetivo, apresenta um tom positivo, mais brando e diferente de, por exemplo, "vontade", semanticamente bastante próximo, que traz os traços do impulso, da compulsão, nem sempre controlável: “cheia de vontade” seria uma qualificação negativa em relação à princesa, negatividade esta que se parece querer evitar:

Desde pequena, ela mostrava como seria. Nem mesmo o rei, a rainha e a rainha avó escapavam de suas tiranias.

Mas talvez tiranias seja uma palavra forte demais, melhor relembrar a história desde o começo. (BIAZETTO, 2012, p. 1).

Ao mencionar tiranias, o narrador abre um frame negativo, em que se projetariam reações de repulsa quanto à personagem e de não adesão à identificação com ela. Pode-se afirmar, portanto, que a expressão a princesa desejosa cria uma atmosfera favorável à aceitação de uma personalidade marcante (e marcada), mas não menos empática e suscetível de identificação pelo leitor, nem estigmatizada. É uma representação propensa à patemização, ao desencadeamento de emoções, graças aos valoresa ela atrelados, e, outra vez, disseminada pela recorrência ao ideal "principesco" que se perpetua com mais essa história.

Também as metáforas revelam importante capacidade de exacerbação de qualidades, ao aproximarem elementos de diferentes domínios em função 
da característica que lhes é comum. Em outras palavras, por meio da iconicidade, as expressões metafóricas colocam em evidência sentidos normalmente insignificáveis, mas possivelmente apresentáveis e inferíveis, como os relativos às sensações e aos sentimentos. A metáfora, muito mais do que ornamento do discurso, pode ser entendida como a qualificação operada por um elemento concreto (que pode ser representado por um substantivo; às vezes, por um adjetivo; ou por uma imagem) o qual se constitui como traço qualificador que se pretende salientar; a metáfora pode ser vista como o autêntico mecanismo de qualificação implícita. Fiel à proposta de caracterização da protagonista, assim diz o narrador: "Foi então que o povoado todo fugiu das garras, ou melhor, dos braços desejosos da princesa" (BIAZETTO, 2012, p. 8). O signo "garras" alude à violência do ato de se apoderar de algo, pois indica o instrumento de caça de alguns animais, dotados de unhas fortes e curvas com que capturam e matam suas presas. Por isso o "ajuste” ("ou melhor, dos braços desejosos da princesa”), embora a referência às garras, em certa medida, já cumpra seu papel de caracterizar "colateralmente" sua atitude como opressora, ou violenta.

A transposição de qualidades também ocorre em comparações, embora, nesse caso, adote uma via mais indireta, em função do distanciamento operado pelo nexo comparativo. Ainda assim, vale mencionar o exemplo: "Até que um dia de pouco vento e de muita quietude, a princesa sentiu algo de muito estranho. Algo tão forte como dor de espinho" (BIAZETTO, 2012, p. 12). Da mesma maneira, a aproximação entre o sentimento da princesa e a dor de espinho faz com que emerja um sentido indizível, não passível de "revestimento sígnico", apenas subentendido, mas que pode ser referido por meio da alusão à dor física, pois semelhante em seu sofrimento e intensidade. A caracterização desse sentimento, portanto, se faz por meio de uma implicitação. Esse recurso também está presente em "Esse desejo foi crescendo... ficando enorme, tão grande que já não tinha espaço dentro dela para crescer. Então transbordou" (BIAZETTO, 2012, p. 12). E transbordou sob a forma de um rio em que se transformaram as lágrimas da princesa. Essa concretização, um pouco metáfora, um pouco pura ficção, permite que se entenda um sentimento em termos de algo palpável, que se pode conter (ou não) em um limite imposto fisicamente. Sua categorização como metáfora, ou como elemento ficcional vai depender da leitura empreendida, mas, em sua constituição, a expressão se abre a ambos os sentidos. 
A alusão a outras histórias é igualmente um recurso de aproximação de qualidades em virtude do entorno conformadorinseparável do intertexto. No caso de A princesa desejosa, a alusão é realizada de modo implícito e, assim, exige conhecimento extratextual geralmente acionado apenas pelo adulto leitor, ou mediador da leitura. É uma estratégia de implicitação qualitativa projetada pela textualização.

O Príncipe Viajante, era assim que o chamavam, viajou quarenta dias e quarenta noites por águas agitadas e perigosas, pois o desejo da princesa não parava de crescer. [...]

Os dois, então, passaram mil e uma noites conversando.

E depois decidiram se casar. (BIAZETTO, 2012, p. 16-18).

"Quarenta dias e quarenta noites" é uma medida temporal recorrente, mencionada no texto bíblico inclusive, que serve como representação de sofrimento: é um período longo e de mesma medida, por exemplo, do vivido por Jesus Cristo antes de sua crucificação e por Noé em sua arca por causa do dilúvio. No conto em análise, é o período de grande aflição da princesa em sua solidão e da busca do príncipe, que, como Noé, enfrenta águas tortuosas. Além disso, assim como nessas histórias, após o período de sofrimento, vem o da "bonança", como também acontece com a princesa e pode ser esperado a partir da expectativa criada por essa aproximação intertextual. Já "passaram mil e uma noites conversando" remete ao período em que Sherazade engana o Sultão com suas histórias a fim de ele poupar sua vida. Ainda que o texto bíblico e as Mil e uma noites não sejam explicitamente referenciados, nem fielmente reproduzidos em seus elementos, são constructos que constituem o imaginário sociocognitivo dos leitores e que, em função de mais essa recorrência, são difundidos. O leitor exposto a esses saberes constitui-se como tal de acordo com valores e crenças atribuídos aos elementos referidos como repertório que o capacita à pertença ao grupo.

Essas observações levam a outros aspectos, agora relacionados aos signos imagéticos, que também podem ser considerados codificados e metafóricos. As ilustrações codificadas são signos imagéticos alçados a símbolos, em virtude de seu reconhecimento como representantes de uma parcela da realidade maior do que sua referência direta a um elemento isolado do mundo (BARTHES, 1990). O simbolismo é adquirido por uma imagem 
como um sentido segundo, mais amplo e abstrato, adicionado à referência mais direta que o signo imagético, em função de sua semelhança física, faz a um elemento do mundo. Torna-se codificada a ilustração que é interpretada através do imaginário sociodicursivo em que se insere, com um sentido categorial predominante a que se submete sua aparência individualista. Nesse caso, a imagem pode ser considerada altamente codificada, dada a complexidade de sua interpretação, que exige um conhecimento de mundo para além do reconhecimento do aspecto físico do objeto que representa, e dado o amplo alcance de seu sentido, partilhado pelos grupos sociais. Em função das evocações que permite e dos sentidos culturais nela imputados, a ilustração codificada é passível de forte implicitude qualitativa. Diferentemente desse mecanismo, na metáfora visual, o signo imagético recebe, em seu cotexto, um sentido determinado pela similaridade entre dois domínios que, de certa maneira, são sobrepostos, a fim de tornar evidente uma qualidade.

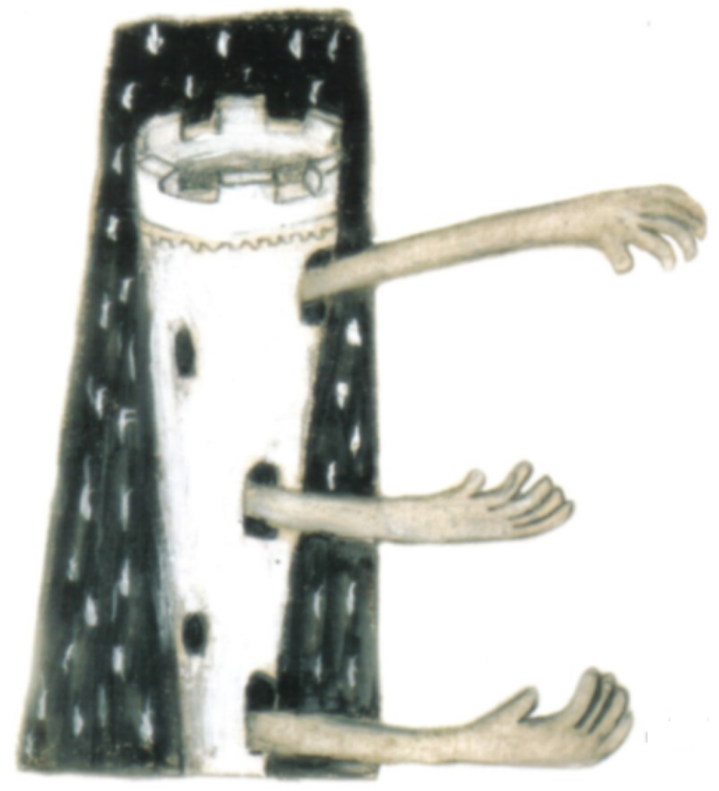

Figura 1 (BIAZETTTO, 2012, p. 1) 


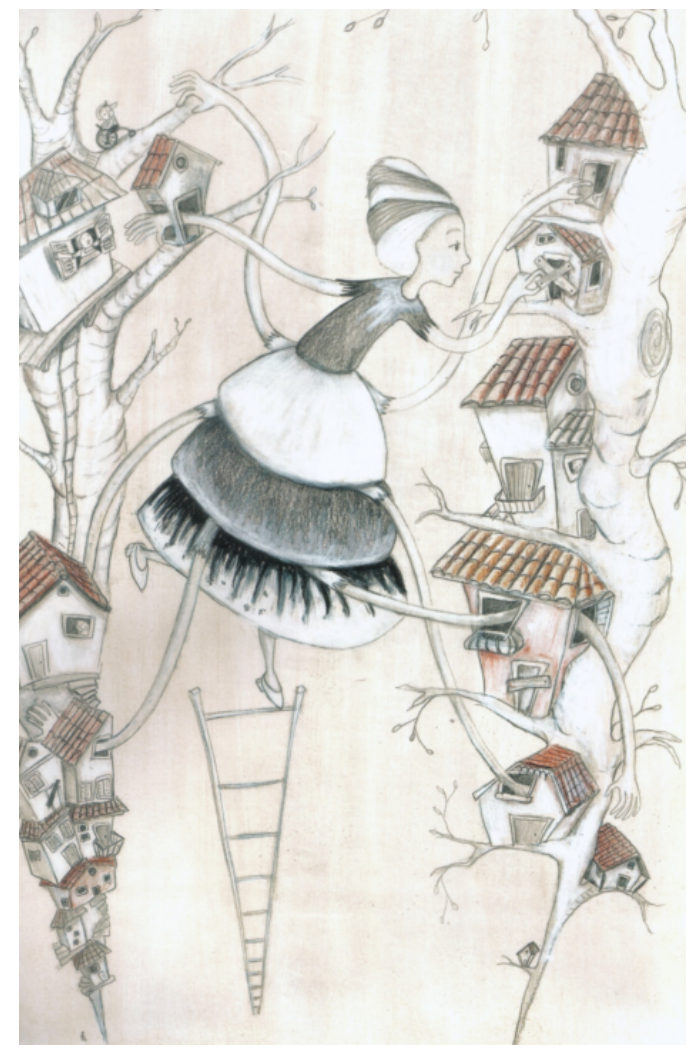

Figura 2 (BIAZET'TO, 2012, p. 6)

A capitular "E" que abre a narrativa (Fig.1) tem a forma de uma torre de castelo de onde saem três braços que se alongam como se quisessem alcançar algo. A torre do castelo pode ser considerada uma ilustração codificada por causa de sua funçãorepresentacional de uma "cultura monárquica", de um mundo de reinos, princesas e castelos que povoa a imaginação de vasto grupo social. São referências a realidades atualizadas apenas na imaginação e a partir dela. Desse saber decorrem os valores atribuídos aos elementos significados, que possibilitam o acionamento de vários efeitos, inclusive os patêmicos, tão favoráveis à adesão ao conteúdo textual e à inserção social do leitor. Já os três braços que saem da torre constituem uma metáfora visual porque, além de, iconicamente, referirem-se a membros do corpo humano, 
ali representantes metonímicos da princesa (quemora na torre do castelo, como todas as princesas), seu gesto "pedinte" e seu número exagerado para uma pessoa só (três) mostram o forte desejo expresso pela jovem. O desejo, reconhecido pelo gesto; sua intensidade, pela quantidade de braços.

Essas qualidades são reforçadas em outras ilustrações (Fig. 2): a princesa aparece como uma jovem de vestido longo e rodado, com penteado não usual na atualidade, mas semelhante aos de épocas antigas, com dez braços que mexem, ao mesmo tempo, em várias casas empoleiradas em altíssimas árvores. A princesa se equilibra em uma escada, na ponta do pé, a fim de alcançar a última casa. Seu tamanho é agigantado em relação às casas. A imagem da princesa é codificada por se constituir de elementos evocatórios (sua vestimenta e penteado) de uma dada parcela da realidade. Já a inusitada quantidade de braços longos, seu gesto invasivo, seu tamanho agigantado em relação às casas, metaforicamente, suscitam a intensidade de seu desejo e a opressão de sua atitude: a grande quantidade, a forte intensidade; o prolongamento dos braços que invadem as casas e a disparidade dos tamanhos, a opressão do gesto invasivo. Soma-se a isso a disposição das casas, construídas no alto das árvores, numa tentativa de defesa dos habitantes daquele lugar.

O Príncipe Viajante é representado como um rapaz cheio de pernas, cada qual apoiada em um meio de transporte (bicicleta, barco, esqui, avião, automóvel). Da mesma maneira, a grande quantidade de pernas, metaforicamente, mostra a intensidade de sua qualidade aventureira, viajante, curiosa. Já as imagens dos meios de transporte ilustram, simbolizam e justificam a qualidade viajante.

Enfim, as ilustrações desse texto, além de traçar a referência a um mundo da imaginação calcado na realidade física, com jovens e castelos, bicicletas e casas, são, em vários aspectos, altamente codificadas, em virtude da parcela de realidade que representam, além de metaforizarem qualidades não significáveis, mas evocadas pela significação. Além disso, são signos igualmente passíveis de acionar efeitos patêmicos, dada a inserção sociocognitiva de que se valem. Valores negativos e positivos, orientações de natureza cultural e evocações emotivas estão implicadas poeticamente nelas. 


\section{Para Finalizar}

A leitura, como processo de construção de sentido, é direcionada por impulsos ideológicos mais ou menos evidentes, que são "naturalmente" socializados à medida que os homens se tornam indivíduos de uma coletividade. Aprende-se a construir sentido de acordo com a maneira de olhar o mundo observada nos círculos sociais de que se participa. Há códigos linguageiros e interacionais que se agregam às formas significativas e direcionam seu sentido; o sentido não está "pregado" às formas, mas ao direcionamento imposto pelo modo de usar que as subjaz. A leitura, portanto, é aprendida, para além das palavras e imagens, na relação com o contexto sociocognitivo estabelecido no uso que o grupo social faz do aparato significativo. E isso se aprende em conjunto.

... o modo como os textos são organizados e nosso entendimento dessa organização exercem um efeito profundo sobre como vemos o mundo. Nas palavras de Roger Fowler: “os códigos linguísticos não refletem a realidade de maneira neutra; eles interpretam, organizam e classificam os objetos do discurso. Eles corporificam teorias de como o mundo está organizado: visões de mundo ou ideologias. Para o indivíduo, essas teorias são úteis e animadoras, tornando simples e manejável a relação dele [sic] com o mundo". Isto é, se as compreendermos. Pois, como diz Fowler, "no texto contínuo, as orações são ligadas por um sistema intrincado de laços coesos"; e, a menos que estes sejam entendidos, correremos algum perigo de não entender o texto. Ou, como observa Frank Smith, em Writing and the Writer [A escrita e o escritor, 1982]: “Quanto mais inconvencional o leitor considera o texto, menos o leitor tenderá a ter quaisquer expectativas relevantes sobre ele, e menos compreensível ele tenderá a ser". (HUNT, 2010, p. 137-138).

Independentemente de se tratar de livros cujo público-alvo pode também ser constituído por crianças, como textos - e bastante complexos - que são, os livros ilustrados já trazem em si uma "marca cultural", uma indelével orientação do olhar, um modo de compreender o mundo apropriado para/por um grupo social. Todo texto é, de certa maneira, formativo, no sentido de conformar socioculturalmente o indivíduo. A adesão 
- ou não - ao projeto de sentido preparado pelo/no texto depende dessa conformação. Só se atribui sentido ao texto de acordo com essa inserção social, operada na interação texto-leitor. No entanto, as crianças, em início de conformação, se submetem completamente à mediação do adulto, que, aos poucos, lhes mostra um modo de olhar (e, quem sabe, o modo de duvidar do que vê). Para elas, não há sentidos melhores ou piores, prioritários ou secundários: tudo pode ter/ser sentido. E um sentido muito mais aberto à "percepção primeira”, ao sentimento.

Segundo o destaque de Hunt na citação, "quanto mais inconvencional o leitor considera o texto, menos o leitor tenderá a ter quaisquer expectativas relevantes sobre ele, e menos compreensível ele tenderá a ser"; em outras palavras, a compreensão do texto depende dessa conformação, ainda que seja para, mais tarde, se opor ao sentido compreendido. Para a criança, cuja experiência socializadora está apenas começando, pouco há de "convencional" nos textos; pode-se esperar tudo - ou nada. A criação de expectativas, inseparável da interpretação competente, para a criança, pode tornar-se uma dificuldade. Só se criam expectativas a partir do já vivido, do reconhecido. Ou mais aventureiro será o processo leitor, sem garantia de sucesso, ou de uma "meta" para a interpretação que se tenta impetrar. É, portanto, condição para a leitura proficiente, a conformação do leitor, dada inclusive - ou sobretudo - pelos próprios textos e sua textualização. Essa conformação, no entanto, não significa uma formação repetidora e passiva, mas repetidora na medida em que requer a convenção socializadora e fortemente ativa, interativa, gerada na influência mútua que se estabelece entre texto e leitor, entre mediador e "ouvinte", entre "mais formado" e "mais livre para todos os sentidos". Afinal, "ninguém educa ninguém, ninguém educa a si mesmo, os homens se educam entre si, mediatizados pelo mundo" (FREIRE, 1987).

Grande parte das estratégias de leitura necessárias a uma interpretação proficiente e que extrapole as "amarras apassivadoras do texto" depende do modo de olhar que se ensina/aprende na inter-relação com o grupo social. Inseridos em um grupo que olha através dos textos, o leitor em formação estará exposto à tomada de consciência dessas estratégias e à constante e necessária relação com os saberes que vêm do mundo, da vida, da experiência direta com a realidade. Para o desenvolvimento da capacidade leitora, é preciso saber fazer relações em todos os sentidos, para todas as direções. 
Por seu lado, as pesquisas consagradas a uma psicolinguística da compreensão distinguem, na leitura, "o ato léxico" do "ato escriturístico". Mostram que a criança escolarizada aprende a ler paralelamente à sua aprendizagem da decifração e não graças a ela: ler o sentido e decifrar as letras correspondem a duas atividades diversas, mesmo que se cruzem. Noutras palavras, somente uma memória cultural adquirida de ouvido, por tradição oral, permite e enriquece aos poucos as estratégias de interrogação semântica cujas expectativas a decifração de um escrito afina, precisa ou corrige. (CERTEAU, 2012, p. 240).

A observação da qualificação implícita e de seus recursos acionadores pode não só auxiliar a inserçãodo leitor iniciante no contexto cultural em que vive, como também provocar-lhe a sensibilidade e a criticidade. O leitor competente (como deve ser, em primeiro lugar, o formador de novos leitores e os mediadores de leitura) deve ter habilidade de reconhecer e salientar nos textos os elementos provocadores de inferências, sejam elas intelectivas ou afetivas, e suscitar as relações necessárias entre os elementos textuais entre si, ou entre os elementos textuais e os contextuais, com o intuito de evidenciar os índices que levam ao cálculo do sentido e, assim, ao seu posterior questionamento.

\section{Referências}

BARTHES, R. O óbvio e o obtuso: ensaios críticos III. Rio de Janeiro: Nova Fronteira, 1990.

CERTEAU, M. de. A invenção do cotidiano: 1. artes de fazer. 18. ed. Petrópolis: Vozes, 2012.

CHARAUDEAU, P. Grammairedusens et de l'expression. Paris: Hachette, 1992.

CHARAUDEAU, P. Linguagem e discurso: modos de organização. São Paulo: Contexto, 2008.

CHARAUDEAU, P. A patemização na televisão como estratégia de autenticidade. In: MENDES, E.; MACHADO, I. L. (Orgs.). As emoções no discurso. v. II. Campinas: Mercado de Letras, 2010. p. 23-56. 
CHEVALIER, J.; GHEERBRANT, A. Dicionário de simbolos. 2. ed. Rio de Janeiro: José Olympio, 2009.

FREIRE, P. A pedagogia do oprimido. 17. ed. Rio de Janeiro: Paz e Terra, 1987.

HUNT, P. Crítica, teoria e literatura infantil. São Paulo: Cosac Naify, 2010.

KLEIMAN, A. Texto \& leitor. Campinas: Pontes, 2009.

NICOLAJEVA, M.; SCOTTT, C. Livro ilustrado: palavras e imagens. São Paulo: Cosac Naify, 2011. 